\title{
A description of the use of the Interprofessional Assessment Tool and frequency of dietitian referrals among New Westminster Home Health clients
}

\author{
B. Davidson ${ }^{1}$, S. Kalil1, A. Ramanzin1, T. Kafka1, M. LeBlanc², C. Edmunds² \\ 1 UBC DIETETICS PROGRAM, VANCOUVER \\ 2 FRASER HEALTH
}

Introduction: New Westminster Home Health $(\mathrm{HH})$, a community based health service, uses an assessment tool called the Interprofessional Assessment (IPA). One intended purpose of the IPA is to identify clients with needs that could be met by the interprofessional $\mathrm{HH}$ team. Currently, relative to the total number of referrals to $\mathrm{HH}$ services, the frequency of $\mathrm{HH} R D$ referrals is noticeably low. This pilot study investigates current use of the IPA and the frequency of referral to the HH RD.

Figure 1: Home Health referrals from Sept 2016 - 2017

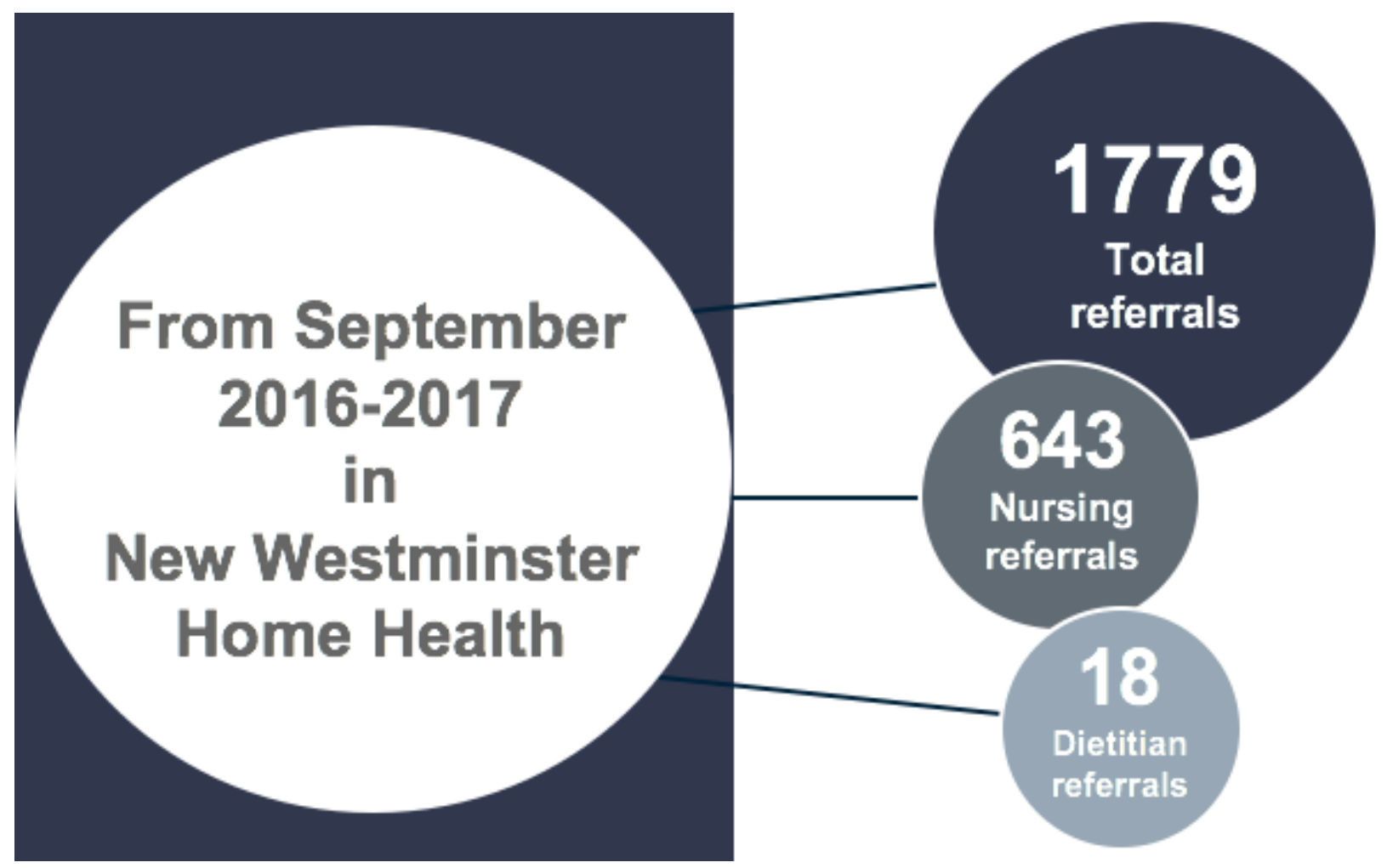

Objectives: This study investigated the frequency of IPA completion, and specifically documentation of nutritionrelated indicators, for clients referred to $\mathrm{HH}$ nursing in New Westminster. Additionally, it investigated the frequency of $\mathrm{HH}$ RD referrals between clients who had a completed IPA and/or documentation of nutrition-related indicators compared to those who did not.

Methods: A retrospective chart review of 349 Primary Access Regional Information System (PARIS) charts was conducted. Variables collected included: reason for $\mathrm{HH}$ referral, age, sex, if the IPA was completed, assessment of nutrition -related indicators, if a referral was made to the HH RD and the reason indicated.

Results: 267 charts (76.5\%) had an IPA completed. Six $(1.7 \%)$ of the 349 charts had referrals to the $\mathrm{HH} R \mathrm{RD}$; of these, four had completed IPAs and two did not. Every completed IPA had a nutrition-related indicator documented. Notable nutrition-related indicators marked as a concern were weight change $(n=93,57.4 \%)$, appetite $(n=45,18.9 \%)$, and diet $(n=31,13.0 \%)$.
Figure 2: Description of IPA completion

\section{Charts Reviewed...}

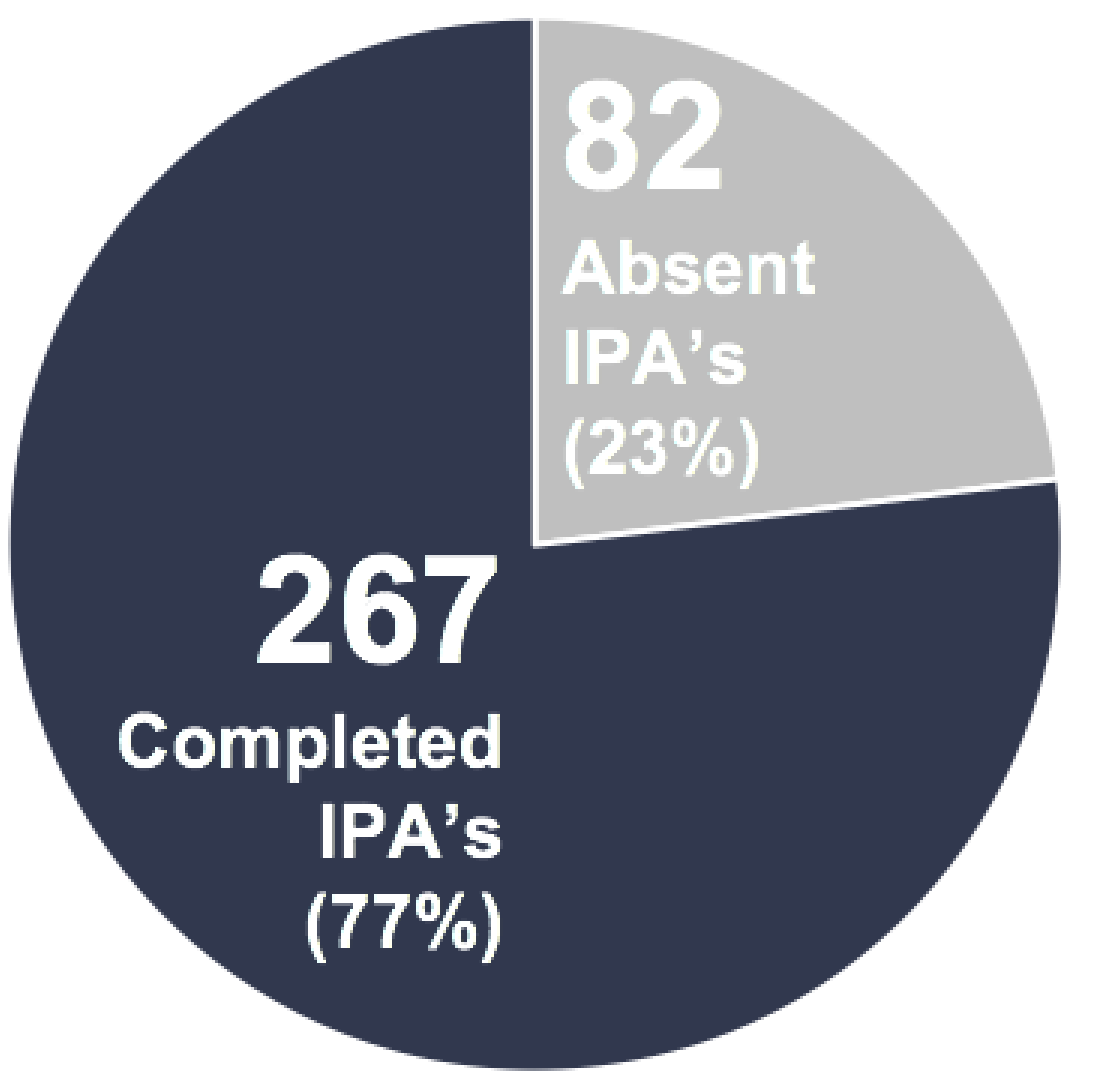

Table 1. Assessment of nutrition-related indicators in the 267 completed IPAs

\begin{tabular}{|l|c|c|}
\hline Nutrition-Related Indicator & $\begin{array}{c}\text { Frequency of } \\
\text { Assessed }\end{array}$ & $\begin{array}{c}\text { Proportion of Assessed Indicators } \\
\text { Marked as "Concern" }\end{array}$ \\
\hline Meal Preparation & 240 & $3.33 \%$ \\
\hline Shopping & 241 & $2.5 \%$ \\
\hline Emotional Status & 232 & $7.8 \%$ \\
\hline Appetite & 238 & $18.9 \%$ \\
\hline Weight Change & 162 & - \\
\hline Diet & 239 & $13.0 \%$ \\
\hline Dental Health & 216 & $6.0 \%$ \\
\hline Feeding & 238 & $2.5 \%$ \\
\hline Swallowing & 233 & $3.9 \%$ \\
\hline Upper Gastrointestinal & 235 & $14.5 \%$ \\
\hline Bowel Management & 246 & $18.3 \%$ \\
\hline Skin Integrity & 238 & $43.3 \%$ \\
\hline Edema & 237 & $26.2 \%$ \\
\hline
\end{tabular}

Conclusions: Despite documented nutrition concerns in the IPAs, many clients were not referred to the HH RD. Though we can conclude this, our study did not investigate potential reasons to explain this observation. Accordingly, this study highlights a need to further explore the use of the IPA, how IPA responses are interpreted by $\mathrm{HH}$ staff, and for standardized guidelines for HH RD referral.

Significance to field of dietetics: Routine nutrition screening of patients in the $\mathrm{HH}$ setting would help to identify patients who are malnourished or at risk of malnutrition who could benefit from RD intervention. 